\title{
Key Factors in Selecting an International Freight Forwarding Company
}

\author{
Yael Perlman*, Tzvi Raz and Livnat Moshka
}

Department of Interdisciplinary Studies, Bar-Ilan University, Ramat-Gan, Israel

\begin{abstract}
Due to globalization, the number of companies operating overseas is constantly expanding along with the organizations offering the capability to deal with the complexities inherent in international trade. Since international freight forwarders (IFF) are considered the main logistic mediator in international trade, selecting an IFF is a significant element in a company's success overseas.
\end{abstract}

This paper examines key considerations among Israeli business executives when selecting an IFF. The conceptual model that was developed describes the relationship between the characteristics of the business environment in which IFF clients operate and the factors affecting the choice of an IFF. Three factors were used to define the client's business environment company size, number of destinations, and the scope of use of IFF services. Two characteristics described respondents seniority and training. After a detailed study of the literature and discussion with long-time IFF users, the authors identified 18 factors in selecting an IFF. These factors were analyzed and then organized in groups in regard to reliability, IFF business environment, information management, service and prices.

The Reliability group was found to be the most important for IFF clients. It was followed by the Service and Prices group. The group of least importance is Information Management.

Data for this study was collected using a questionnaire administered to some 200 organizations. The return rate was about $25 \%$. The questionnaire's reliability (Cronbach's $\alpha$ ) is 0.829 , consistent with the fact that only $6 \%$ of the respondents suggested further reasons for choosing forwarding companies beyond those suggested.

\section{INTRODUCTION}

To remain competitive on a global scale, companies must increasingly rely on the services of intermediate suppliers [1]. The primary logistics middleman for cross-national trade has traditionally been the international freight forwarder (IFF) [2]. In [3], forty percent of 370 respondents in the US stated that IFF companies handle all their international freight. Almost $75 \%$ said that they had been using the services of these companies over the past ten years. Similarly, in [4], $92 \%$ of the companies use IFF services and $75 \%$ of the international freight of these companies is handled by IFF. In short, companies are more keenly aware than ever that their IFF will affect organizational resources, inventory management, and production planning, cash flow and product quality. The process of choosing an IFF company thus becomes a high priority activity in which company officials, primarily logistic managers, compare IFF companies according to a broad set of criteria and factors.

The empirical study presented in this paper examines the key factors affecting the choice of IFF companies, as perceived by their Israeli clientele. The objectives of this study were to identify and rank the key factors for selecting IFF providers; to organize these factors in groups and to rank their importance; and finally, to assess the influence of the client's business environment in selecting an IFF provider. The study's results represent a tool that may help logistics managers in selecting an IFF.

*Address correspondence to this author at the Department of Interdisciplinary Studies, Bar-Ilan University, Ramat-Gan, Israel;

E-mail: perlmay@mail.biu.ac.il

\section{LITERATURE REVIEW}

In this paper we adopt the definition of an international freight forwarder from [3]: "An international trade specialist who can provide a variety of functions to facilitate the movement of cross-border shipments The functions provided by IFF company include: delivery and distribution services; handling payment arrangements; assistance in paperwork required for deliveries; and organizing local and international shipping; information services; insurance; customs services; warehousing and consolidation services [2].

Studies identifying the key factors which are important for IFF clients in freight service selection, international or otherwise, vary since there are many different types of carriers, including: customhouse brokers (CHBs); non-vessel operating carriers (NVOCCs); and export management companies which characterize themselves as third-party logistics providers (TPLs), i.e., external companies performing functions traditionally conducted in-house [5]. In the face of the proliferation of different types of carriers, previous distinctions seem increasingly blurred the more that added responsibilities are taken on [2].

Studies also differ by the research methodology used. The methodology used in this study involved respondents rating a list of factors presented to them in a questionnaire. This methodology was used by [3, 6-8]. Other methods can be found in the literature such as the expert system (ES) developed in [4] and an analytical hierarchy process (AHP) in $[9,10]$. Recently in [11] a theory of reasoned action (TRA) model which assess the actual purchase intention of the respondents was implemented. 
There is a range of different factors deemed important when selecting an IFF and no common opinion emerges from the literature regarding how the selection factors should be grouped. In [12], seven categories: freight rates; reliability; transit time; over-supply, short-supply and damaged; market and carrier considerations; and product characteristics while [7] considered four groups of factors: timing, price, security and service. In [10] it was suggested that selection criteria can be grouped into the following categories: supplier criteria, product performance criteria, service performance criteria and cost criteria.

In [12] a review of eleven empirical studies, it was found that despite the difference in selection factors and how they are categorized, reliability seems to be the most important factor and that forwarding time is more important than freight price.

In [6], Irish freight shippers and suppliers rank a list of service attributes. They found that shippers and freight suppliers employ different criteria in selecting a freight transport service. The most important factor for a freight supplier is the issue of punctuality. However, among shippers, punctuality is second to the ability to respond quickly to any problem.

In [3], American IFF customers rank the following factors in selecting a forwarder: expertise; size; experience with the customer's products; convenience; geographic deployment; company reputation; prices; personal attention; financial stability; number of services; the ability to provide relevant information; and reliability of service. They found reliability to be the most important factor, followed by expertise, with costs ranking sixth.

In [7], Norwegian exporters ranked a broad range of factors arranged in four groups: timing, price, security and service. Cost factors were found to be the most important.

In [8], factors affecting IFF selection as perceived by IFF companies and their customers in the US in 2001 compared to 1991 . The results show that IFF customers in 2001 were more concerned with information access, consistent carrier performance, customer relations and availability of desired services. [11] is the first to consider carrier security. However, the results show that security was the least important among the various factors that were evaluated.

In summary, pervious papers about supplier selection decisions differ in terms of type of carrier studied, methodology, the range of factors considered important and the manner in which these factors are classified.

One aspect which, to the best of our knowledge, has never really been examined, but would seem to be of considerable importance, is the influence of the client's business environment in selecting an IFF.

Most of the studies to date focus on the national aspect. Different national backgrounds impact client's consideration in selecting a supplier [1]. This result was illustrated from a comparison of five countries -- US, UK, Norway, China and Germany - and how they rank nine factors when selecting suppliers. They found that the first priority factor in China, US and UK is quality with delivery performance second. In Germany and Norway, however, just the opposite prevails. It is hoped that this study will contribute to the literature re- garding the Israeli perspective as well as direct academic attention to the environmental element in selecting an IFF.

\section{METHOD}

A two-part questionnaire was formulated and mailed to 200 Israeli exporters and importers that currently use IFF services. These exporters and importers were spread across the whole business spectrum and range from exporters of vegetables and high tech equipment to importers of shoes and ladies handbags. While 200 may not seem particularly high, in terms of the Israeli business scene, this is a substantial figure. A total of 50 viable responses were received resulting in a $25 \%$ percent response rate which is typical for postal surveys of businesses. (See, for example, $[3,7]$ ). In Part 1, the respondent was asked to rank each factor's importance on a 1-5 Likert-type scale $(1=$ "not important", $5=$ "very important"). Part 2 examines the business environment characteristics which are known or assumed to affect logistics and forwarding decisions.

In this study, 18 factors (see Table 1) for selecting an IFF provider were identified. All the factors, apart from Classification Retention and Taxation, are mentioned in the literature reviewed in the previous section. Classification Retention measures the IFF's ability to create a classification database for each client for custom duties. This classification can be used by the client in order to reduce the amount of custom duties paid, by choosing categories that are tax-free. Taxation measures the forwarder's ability to minimize taxes borne by the client. We included those two factors since the forwarder's ability in dealing successfully with taxes and duties facing Israeli exporters can create considerable added value in terms of reduced international forwarding costs.

A factor analysis resulted in four factor groups used to develop four dependent variables:

Group I - Reliability included the reliability of service, reliable information and deadlines factors, with a Cronbach alpha reliability of 0.870 .

Group II - IFF Company's Business Environment included size, quality certification, business experience and additional logistics services factors, with a reliability of 0.815 .

Group III - Information Management included online pricing, reporting tools, classification retention and information availability, with a reliability of 0.839 .

Group IV - Service and Prices included customization, personal attention, expertise flexibility and competitive prices with a 0.609 reliability rating.

Group criteria, factors in each group along with their loading factors are summarized in Table $\mathbf{2}$.

The factor "Taxation" was not included in any of the four groups since its loading factor was low. This factor was treated as an individual dependent variable.

To study the influence of business environment characteristics on the clients of IFF companies regarding these group criteria, we selected five characteristics which we used to develop five independent variables: company size; scope of use of IFF services; number of destinations; respondent's seniority and training. 
Table 1. IFF Evaluation Factors

\begin{tabular}{|c|c|}
\hline Factor & Explanation \\
\hline Expertise & Degree of expertise in providing relevant services \\
\hline Customization & Ability to meet unique customer requirements \\
\hline Flexibility & Ability to provide both air and sea freight services \\
\hline Reliability & Reliability of the IFF's service \\
\hline Meeting Deadlines & How well the IFF meets pickup, delivery and distribution deadlines \\
\hline International Deployment & No. of branches/offices worldwide; no. of countries in which the IFF is represented \\
\hline Quality certification & How well the IFF meets ISO 9002 and IATA and FIATA standards \\
\hline Reliable information & The reliability of IFF's information systems \\
\hline Online pricing & The ability to receive price quotes over the Internet \\
\hline Reports tools & The customer's ability to produce status reports independently \\
\hline Competitive prices & Ability to offer attractively priced services \\
\hline Taxation & Ability to minimize the customer's tax payments \\
\hline Classification retention & Ability to create a customs classification data base \\
\hline
\end{tabular}

\section{Firm Size}

Firm size has been used as differentiating variable in previous choice of transport studies. (See, for example, $[3,7,13])$. Results in pervious studies were not consistent, in [3], it was found that larger firms assign greater importance to IFF's expertise and reliability. However their results indicated highly similar rankings between larger and smaller firms. In this study, three categories are used to classify the client's company size: up to 50 employees, 50 to $200 \mathrm{em}-$ ployees, more than 200 employees.

\section{Scope-of-Use}

A recent study found that some IFF companies begin by offering value added services and move towards becoming a logistics service provider [2]. The evolution of the concept of "total logistics support" led IFF companies to offer value added services such as customs clearance, logistics management, information technology and more $[2,13]$. In order to measure to what extent clients purchase the additional services that IFFs offer, we defined scope-of-use of IFF services. We employ scope-of-use as a segmentation tool and define three categories which classify scope-of-use in this study: (1) international forwarding only; (2) a complete "solution" for all of an organization's logistics requirements; (3) international forwarding requirements and part of the organization's logistics requirements

\section{Respondent Seniority}

We defined a senior respondent as one who was ten or more years in present position. Respondent seniority
Table 2. IFF Selection Group Criteria

\begin{tabular}{|c|c|c|}
\hline Group Criteria & Factor & Factor Loadings \\
\hline \hline \multirow{3}{*}{ Reliability } & Reliability of service & 0.861 \\
& Reliable information & 0.842 \\
& Meeting deadlines & 0.805 \\
\hline \multirow{3}{*}{ Service and } & Customization & 0.874 \\
Prices & Personal attention & 0.408 \\
& Expertise & 0.576 \\
& Flexibility & 0.502 \\
Information & Competitive pricing & 0.172 \\
\hline Management & Online pricing & 0.876 \\
& Reporting tools & 0.871 \\
& Classification retention & 0.798 \\
& Information availability & 0.383 \\
\hline \multirow{3}{*}{ IFF business } & IFF size & 0.832 \\
environment & International deployment & 0.836 \\
& Quality certification & 0.814 \\
& Experience & 0.674 \\
& Additional logistic services & 0.556 \\
\hline
\end{tabular}

measured by the length of time in one's position has been used as a differentiating variable in [3]. They found that less experienced respondent assign greater importance to expertise and prices. On the other hand they found a very high degree of similarity in within group ranking. 


\section{Number of Destinations and Respondent Training}

The characteristics "number of destinations" and "respondent training" were chosen as differentiating variables in this study although they do not appear in previous transport choice studies. We used these factors as differentiating variables in regard to a particular company and respondent characteristic since we assumed they affect decisions about logistics and forwarding matters. A small number of destinations may impact the dependence of the company on the IFF provider while respondent training is assumed to have influenced a respondent's knowledge and skill.

The relationships regarding the influence of the five independent variables on the four groups (dependent variables) are described in five propositions.

$\mathrm{P}_{1}$ : IFF selection groups will be influenced by a client's company size.

$\mathrm{P}_{2}$ : $\quad$ IFF selection groups will be influenced by the range of services the client may purchase from an IFF.

$\mathrm{P}_{3}$ : $\quad$ IFF selection groups will be influenced by the number of import/export destinations of the client.

$\mathrm{P}_{4}$ : IFF selection groups will be influenced by client seniority.

$\mathrm{P}_{5}$ : IFF selection groups will be influenced by the client's training.

\section{RESULTS AND DISCUSSION}

\section{Respondent Profile}

Of the fifty respondents who participated in the study, $20 \%$ were junior executives; some $13 \%$ were senior executives; and the rest mid-level executives. It appears that among Israeli exporters and importers, mid-level management usually makes forwarding decisions (as shown also in [7]). Most (60\%) of the respondents had some postsecondary education; $30 \%$ had secondary education; and $10 \%$ had a second or third academic degree. Most (58\%) had also received relevant professional training over the three years prior to the study.

The mean seniority was 8.09 years, albeit with a high standard deviation of 6.92. More than a third (39\%) had a 0 5 -year seniority and 35\% had a 5-10-year seniority; The rest (26\%) had been working for their company for more than ten years.

Forty-two percent of the respondents were working in organizations with up to fifty employees; $20 \%$ in organizations employing 50-200 workers; and the rest (38\%) were employed by large organizations with more than 200 employees.

In most cases $(68 \%)$, the service provided by the IFF was international forwarding alone. In $20 \%$ of the cases, part of the service included logistics while in $12 \%$ the IFF provided a complete solution for all the logistics services.

The mean number of export and import destinations was 12 , with a high standard deviation of $11.38 \%$ of the companies had ten destinations or more while $38 \%$ had up to five destinations and $24 \%$ had five to ten.
Table 3. Importance of IFF Selection Factors

\begin{tabular}{|l|c|c|c|c|}
\hline \multicolumn{1}{|c|}{ Factor Name } & Mean Rating & SD & Min & Max \\
\hline \hline Reliability of service & 4.78 & 0.648 & 1 & 5 \\
\hline Deadlines & 4.72 & 0.701 & 1 & 5 \\
\hline Competitive prices & 4.70 & 0.647 & 2 & 5 \\
\hline Reliable information & 4.66 & 0.798 & 1 & 5 \\
\hline Expertise & 4.62 & 0.602 & 3 & 5 \\
\hline Customization & 4.58 & 0.575 & 3 & 5 \\
\hline Personal attention & 4.46 & 0.676 & 3 & 5 \\
\hline Taxation & 4.40 & 0.881 & 2 & 5 \\
\hline Flexibility & 4.18 & 0.983 & 2 & 5 \\
\hline International deployment & 4.06 & 1.029 & 1 & 5 \\
\hline Information availability & 3.94 & 0.998 & 1 & 5 \\
\hline Quality certification & 3.90 & 1.147 & 1 & 5 \\
\hline Additional logistic services & 3.84 & 1.076 & 1 & 5 \\
\hline Business experience & 3.70 & 1.093 & 1 & 5 \\
\hline Classification retention & 3.59 & 1.098 & 1 & 5 \\
\hline Reporting tools & 3.52 & 1.249 & 1 & 5 \\
\hline Online pricing & 3.26 & 1.157 & 1 & 5 \\
\hline Size & & 1.193 & 1 & 5 \\
\hline
\end{tabular}

\section{PERCEPTIONAL ANALYSIS}

Eighteen IFF selection factors were included in this study. Their statistics are presented in Table 3. The three most important factors are reliability $(M=4.78 ; S D=0.648)$, Meeting Deadlines $(4.72 ; 0.701)$ and Competitive Prices (4.70;0.647). All scores ranged between 1 and 5 .

These findings are similar to those reported in $[3,12]$. The Meeting Deadlines factor was also found to play a pivotal role in previous studies [7]. Finally, as with our study, in [7] Competitive Prices is the most important price factor.

As in [7], in which no single dominant service factor was found, we also didn't find any significant difference between three of our four service factors: Expertise, Customization and Personal attention (ranked fifth, sixth and seventh, respectively).

After having ranked the given factors, our respondents were asked to list other factors which were not included in the survey. Most (94\%) did not add any other factors. The questionnaire's reliability (Cronbach's $\alpha$ ) is 0.829 .

Five groups were defined as a result of factor analysis: reliability, IFF business environment, information management services and prices. The ranking of the group importance in presented in Table 4.

The Reliability group was the most important, with a mean of $\underline{4.72}$ and a standard deviation of 0.640 . This group comprised reliability of service, reliable information and meeting deadlines. The literature indicates that these factors are very important factors $[3,12]$. 
The next group was Service and Prices $(M=4.51 ; S D=$ 0.445). McGinnis (1997) also found that reliable service is usually more important than freight rates.

Business Environment ranked third $(M=\underline{3.75} ; S D=$ 0.835). The least important group was Information Management $(M=\underline{3.60} ; S D=0.946)$. Information management group comprised online pricing, reporting tools, classification retention and information availability. This result suggests that respondents take information tools for granted and assume that these services are given anyway.

Table 4. Importance of IFF Selection Groups

\begin{tabular}{|c|c|c|}
\hline Group Criteria & Mean Rating & $\begin{array}{c}\text { Cronbach Alpha } \\
\text { Reliability }\end{array}$ \\
\hline \hline Reliability & 4.72 & 0.87 \\
\hline Service and Prices & 4.51 & 0.609 \\
\hline IFF business environment & 3.75 & 0.815 \\
\hline Information Management & 3.60 & 0.839 \\
\hline
\end{tabular}

\section{EVALUATION OF PROPOSITIONS}

Each of the five propositions described earlier was tested using the Spearman's correlation for the continuous independent variables and independent samples T-tests and oneway ANOVA for the independent grouping variables.

Only one proposition with respect to number of destinations was supported. It was found that the Reliability group and the Service and Prices group are significantly more important to clients who export/import from and to a smaller number of destinations than to clients with a larger number of destinations. Results are presented in Tables $\mathbf{5}$ and $\mathbf{6}$.

The evaluation of the propositions implies that the aggregated data regarding the importance of IFF selection factors (see Table 3) and the importance of IFF selection groups (see Table 4) are sound and are not influenced by the client's business environment.

Table 5. Correlation Analysis

\begin{tabular}{|c|c|c|c|}
\hline \multirow{2}{*}{$\begin{array}{c}\text { Group } \\
\text { Criteria }\end{array}$} & \multicolumn{3}{|c|}{$\begin{array}{c}\text { Business Environment Characteristics } \\
\text { (Continuous Variables) }\end{array}$} \\
\cline { 2 - 4 } & $\begin{array}{c}\text { Company } \\
\text { Size }\end{array}$ & $\begin{array}{c}\text { Number of } \\
\text { Destinations }\end{array}$ & $\begin{array}{c}\text { Respondent's } \\
\text { Seniority }\end{array}$ \\
\hline \hline Reliability & -0.009 & $-0.504 * *$ & 0.096 \\
\hline Service and Prices & -0.055 & $-0.329 *$ & -0.039 \\
\hline $\begin{array}{c}\text { Information } \\
\text { management }\end{array}$ & 0.043 & -0.269 & 0.117 \\
\hline $\begin{array}{c}\text { IFF business } \\
\text { environment }\end{array}$ & 0.069 & 0.040 & -0.073 \\
\hline
\end{tabular}

\section{CONCLUSIONS}

The factor perceived as most important to Israeli international traders is Reliability. This observation is supported by the literature. We also found that the Reliability group of factors is the most important, with an average of 4.72 which indicates that, overall, this group is very important to respondents. The second most important perceived factor is Deadlines. The ability of forwarders to meet deadlines directly affects their clients' ability to meet their own obligations towards their customers and to provide them with reliable supply schedules. Note that this factor is also related to reliability, as shown in our factor analysis.

Table 6. Analysis of Variance \& Independent Sample T-Test

\begin{tabular}{|c|c|c|}
\hline \multirow{2}{*}{ Group Criteria } & \multicolumn{2}{|c|}{$\begin{array}{c}\text { Business Environment Characteristics } \\
\text { (Grouping Variables) }\end{array}$} \\
\cline { 2 - 3 } & $\begin{array}{c}\text { Range of Service the Client } \\
\text { Purchase from an IFF }\end{array}$ & $\begin{array}{c}\text { Client's } \\
\text { Training }\end{array}$ \\
\hline \hline Reliability & $\mathrm{F}(2,47)=2.464$ & $\mathrm{t}(48)=1.411$ \\
\hline Service and Prices & $\mathrm{F}(2,47)=0.738$ & $\mathrm{t}(48)=0.151$ \\
\hline $\begin{array}{c}\text { Information } \\
\text { management }\end{array}$ & $\mathrm{F}(2,47)=0.788$ & $\mathrm{t}(48)=0.330$ \\
\hline \multicolumn{2}{|c|}{$\begin{array}{l}\text { IFF business } \\
\text { environment }\end{array}$} & $\mathrm{F}(2,47)=0.246$ \\
\hline
\end{tabular}

The third most important factor is Competitive Prices. In addition, the Service and Prices group ranks second in importance with a 4.51 average. Selecting an IFF company is basically an economic decision, based, to a large extent, on cost considerations.

Our analysis suggests significant differences in regard to the number of destinations a client may have. We found that the importance of the Reliability group and Service and Prices group is significantly higher for respondents who work in a company with a smaller number of destinations. Finally, our findings did not support other relationships between the client's business environment and group of factors. Consequently the study suggests that the aggregate data regarding the group criteria is sound and not influenced by respondent characteristics and the business environment.

The present study investigated the perception of IFF customers as to the most important factors in selecting an IFF service provider. Future research might examine the importance of key factors from the viewpoint of the freight service providers and then to compare the different perceptions of providers and clients. Another area for further research would be to repeat the present study using a different sampling frame, which would examine whether the results would be similar or different among IFF users from other countries.

\section{REFERENCES}

[1] D. Wang, Y. Tian, and Y. Hu, "Empirical study of supplier selection strategies across the supply chain management in manufacturing companies", International Engineering Management Conference, Proceedings, 2004, pp 85-89.

[2] V. Markides, and M. Holweg, "On the diversification of international freight forwarders A UK perspective", Int. J. Physic. Distr. Logist. Manag., vol. 36, pp. 336-359, 2006.

[3] P.R. Murphy and J.M. Daley, "Investigating selection criteria for international freight forwarders", Transp. J., vol. 37, pp. 29-36, 1997. 
[4] A. Özsomer, M. Mitri, and S.T. Cavusgil, "Selecting an international freight forwarder: an expert system application", Int. J. Physic. Distr. Logist. Manag., vol. 23, pp11-22, 1993.

[5] R.C. Lieb, R.A. Millen, and W.L.N. Van, "Third-party Logistics Services: A Comparison of Experienced American and European Manufactures", Int. J. Physic. Distr. Logist. Manag., vol. 23, pp.35-44, 1993.

[6] S.M. Matear, and R. Gray, "Factors influencing freight service choice for shippers and freight suppliers", Int. J. Physic. Distr. Logist. Manag., vol. 23, pp. 25-36, 1993.

[7] E.L. Pedersen, and R. Gray, "The transport selection criteria of norwegian exporters", Int. J. Physic. Distr. Logist. Manag., vol. 28, pp. 108-116, 1998.

[8] S.R. Premeaux, "Motor carrier selection criteria: perceptual differences between shippers and motor carriers", Transp. J., vol. 42, pp. 28-38, 2002.
[9] M.M. Akarte, N.V. Surendra, B. Ravi, and N. Rangaraj, "Webbased casting supplier evaluation using analytical hierarchy process", J. Operat. Res. Society., vol. 52, pp. 511-522, May 2001.

[10] C. Kahraman, U. Cebeci, and Z. Ulikan, "Multi-criteria supplier using fuzzy ahp", Logist. Info. Manag., vol. 16, pp. 382-395, 2003.

[11] M.D.Voss, T.J. Page, B. Keller, and J. Ozment, "Determining important carrier attributes: a fresh perspective using the theory of reasoned action", Transp. J., vol. 45, pp.7-19, 2006.

[12] M. A. McGinnis, "A comparative evaluation of freight transportation choice models", Transp. J., vol. 29, pp.36-46, 1989.

[13] P. R. Murphy, and J.M. Daley, "Profiling international freight forwarders: an update", Int. J. Physic. Distr. Logist. Manag., vol. 31, pp. 152-159, 2001.

(C) Sumathi Suresh; Licensee Bentham Open.

This is an open access article licensed under the terms of the Creative Commons Attribution Non-Commercial License (http://creativecommons.org/licenses/by$\mathrm{nc} / 3.0 /$ ) which permits unrestricted, non-commercial use, distribution and reproduction in any medium, provided the work is properly cited. 